\title{
Are subalpine species' seedling emergence and establishment in the alpine limited by climate or biotic interactions?
}

\author{
Ingrid Dahle ${ }^{1}$, Ragnhild Gya ${ }^{1,2}$, Joachim P Töpper ${ }^{1,3}$, and Vigdis Vandvik ${ }^{1,2,3}$ \\ ${ }^{1}$ Department of Biological Sciences, University of Bergen \\ ${ }^{2}$ Bjerknes Centre for Climate Research, University of Bergen \\ ${ }^{3}$ Norwegian Institute for Nature Research
}

January 20, 2022

\begin{abstract}
Plants are responding to climate change by shifting their ranges to higher elevations. These range shifts are not happening at the same rate for all species, for example, subalpine species are generally moving faster upslope than alpine species, but with large variation within groups. This asymmetry in migration rates will result in novel communities and interactions between plant species that have not previously co-occurred. While seed dispersal is obviously critical for species' range shifts, seedling emergence and survival are also major bottlenecks for successful colonization in new areas. As seedlings generally constitute the most vulnerable stages in the life-history of plants, variation in seedling establishment success can potentially be important determinants of species' range shift rates. Previous studies have found that warming per se tends to increase seedling establishment in alpine climates, but it also increases plant productivity and thus competition for nutrients and light from the resident vegetation, which acts limiting on seedling establishment. This study will attempt to disentangle the relative importance of these abiotic and biotic factors on sub-alpine species' seedling emergence and survival in alpine habitats, to help further understanding and prediction of future lowland plant colonization in alpine habitats. We will also explore if species' life strategies impact their ability to colonize new locations, predicting that species with resource acquisitive traits will emerge earlier and faster than resource conservative species. To address these questions, we will perform a seed transplant experiment where we assess seedling emergence and establishment in the alpine. Seeds will be sown in plots with and without experimental warming, crossed with manipulation of biotic interactions, and using seeds from both resource conservative and resource acquisitive subalpine species. In addition, we will explore if the observed responses are general or context-dependent by replicating this experiment along a regional bioclimatic precipitation gradient.
\end{abstract}

\section{Hosted file}

Dahle_etal_AreSubalpine.pdf available at https://authorea.com/users/455922/articles/553151are-subalpine-species-seedling-emergence-and-establishment-in-the-alpine-limited-byclimate-or-biotic-interactions 